\title{
Correction to: Diversity of culturable bacterial communities in the intestinal tracts of goldfish (Carassius auratus) and their ability to produce $\mathrm{N}$-acyl homoserine lactone
}

\author{
Haruo Sugita $^{1} \cdot$ Shun $_{K^{\prime}}$ Sao $^{1} \cdot$ Satoshi Narisawa $^{1} \cdot$ Ryosuke Minamishima $^{1} \cdot$ Shiro Itoi $^{1}$
}

Published online: 26 October 2017

(C) Institute of Microbiology, Academy of Sciences of the Czech Republic, v.v.i. 2017

Erratum to: Folia Microbiol (2017) 62:263-267

https://doi.org/10.1007/s12223-017-0498-7

In the original publication, the number of the NCTC strain used was published incorrectly. The authors apologize for the error. The error has no effect on the validity of the results and is corrected for accuracy. The correct reference should read as follows:

Page 264, column 2, last paragraph, first to fourth lines should read as follows: "The AHL-producing ability of isolates was determined by cross-streaking against Chromobacterium violaceum strain NCTC 13278 (=CV026) as the AHL biosensor (Swift et al. 1997)."

The online version of the original article can be found at https://doi.org/ 10.1007/s12223-017-0498-7

Haruo Sugita

sugita.haruo@nihon-u.ac.jp

1 Department of Marine Science and Resources, Nihon University,

Kameino 1866, Fujisawa 252-0880, Japan 